"Today's shook me up a lot insideit's definitely changed me": emotional responses and transformative learning through working with disadvantaged communities

\author{
Hanks, Sally
}

http://hdl.handle.net/10026.1/16485

10.1080/14739879.2020.1819170

Education for Primary Care

Taylor \& Francis

All content in PEARL is protected by copyright law. Author manuscripts are made available in accordance with publisher policies. Please cite only the published version using the details provided on the item record or document. In the absence of an open licence (e.g. Creative Commons), permissions for further reuse of content should be sought from the publisher or author. 
“Today's shook me up a lot inside...it's definitely changed me": emotional responses and transformative learning through working with disadvantaged communities

Hilary Neve (corresponding author)

Peninsula Medical School, Faculty of Health, University of Plymouth, Plymouth, UK

@hilary_neve $\quad$ www.linkedin.com/in/hilaryneve/

ORCID 0000-0003-1831-9821

\section{Correspondence details}

C413 Portland Square, Drake Circus, Plymouth, PL4 8AA, UK

Tel: 01752586802

hilary.a.neve@plymouth.ac.uk

\section{Sally Hanks}

Peninsula Dental School, Faculty of Health, University of Plymouth, Plymouth, UK

@HanksSalshanks

ORCID 0000-0002-4072-4594

\section{Miranda Heath}

University of Edinburgh, School of Philosophy, Psychology and Language Sciences, Edinburgh, $U K$

@MirandaGHeath www.linkedin.com/in/miranda-g-heath

ORCID 0000-0003-0115-0978

\section{Wendy Smith}

Well Connected, Plymouth. https://wellconnecteduk.org 


\title{
“Today's shook me up a lot inside...it's definitely changed me": emotional responses and transformative learning through working with disadvantaged communities
}

\begin{abstract}
Background: While undergraduate curricula should reflect populations' priority health needs and promote social accountability, evidence about the impact of such interventions is limited

Aim: To gain insights into students' lived experiences of social engagement pathways and associated learning

Method: Medical and dental students spent four days with local organisations working with disadvantaged groups, recording audio-dairies after each session. These were transcribed, coded and analysed thematically
\end{abstract}

Results: Fourteen students produced 50 audio-reflections. Key themes included emotions, learning and critical reflection. Students reported improved communication skills, better appreciation of others' lives and having their assumptions challenged. They questioned issues underpinning inequalities. Analysis revealed a three-act pathway structure, with students' emotional responses changing as projects progressed.

Discussion: Immersion in new contexts; connecting with others; having their views challenged and plans going wrong appeared to facilitate shifts in thinking, as did experiencing negative emotions. Feedback and support from organisations, facilitators and service users helped students overcome challenges, which was associated with positive emotion.

Conclusion: Educators often work hard to make learning 'easier' for students. This study suggests that when exploring the social determinants of health within community settings, supporting students to experience such unsettling contexts and negative emotions may facilitate transformative learning.

Keywords: transformative learning; social engagement; social accountability; audio-diaries; social determinants of health 


\section{Background}

Social accountability and the importance of producing doctors ready to meet society's needs, now and in the future is recognised internationally as a responsibility of schools who train health professionals [1,2]. The Training for Health Equity Network (THEnet) identifies three important elements. Firstly, curricula should reflect the priority health needs of populations, particularly those in greatest need. Secondly, schools should work in genuine partnership with communities to design and deliver programmes and thirdly, they should promote health equity, addressing avoidable disadvantage in health and in access to health care. Many medical schools across the world are developing social accountability programmes, yet there is a lack of published evidence about the impact of these [3]. There are indications that students develop a better understanding of holistic care, local health needs, the importance of advocacy and the impact of social context on health $[3,4]$. However, they may not develop a sense of personal responsibility to the community [4]. Some studies, mainly in rural areas, describe subsequently improved attitudes towards generalist careers [3].

In dental education, social accountability has been called 'the missing link' [5], with a 2016 study finding that dental students felt no professional obligation to address oral health inequalities [6]. A recent report from our own dental school suggests working with people experiencing homelessness can increase students' understanding of their complex needs [7].

This led to a call, in this journal, for similar mandatory programmes in undergraduate medical programmes [8].

\section{Our setting}


At the University of Plymouth, all $2^{\text {nd }}$ year dental and $3^{\text {rd }}$ year medical students undertake four-day social engagement pathways as part of the core curriculum. These are developed and supported by a local health charity, Well Connected (https://wellconnecteduk.org/), which has long-established community networks. Students work with various local organisations and their clients, to learn about the population group's needs and co-collaborate with them to develop a health-themed intervention. Well Connected facilitators meet regularly with students during their pathways, providing guidance, feedback and support. Interventions aim to address the needs of users as well as offer students further insights into the groups' lives and health issues. Boxes 1 and 2 describe the pathways and provide examples of interventions delivered by students

We aim for these experiences to a) challenge and deepen students' views and assumptions about the health needs of different community groups and b) encourage them to consider the relevance of this learning to the wider population and their future roles as health professionals. Informal evaluation suggested that some students were experiencing significant shifts in their thinking about disadvantage, prompting this study. At the end of each year, students present their project and intervention at a symposium, attended by fellow students and staff. A panel comprising a public health professional, a GP or dentist and community members judges the students' presentations. This assessment is formative. The symposium was not part of this audio-diary study.

[Box 1 near here]

[Box 2 near here]

\section{Study Aim}


This qualitative study aimed to gain insights into students' lived experiences of social engagement pathways and associated learning, including:

- Students' responses to the experiences

- Shifts in understanding and any troublesome learning [9]

- Factors they perceive as enabling or impeding learning

\section{Methodology}

The study utilised talk-aloud audio diary methodology [10], which we have previously found to be easy for participants and can provide valuable insights into students' learning experiences [11]. All medical and dental students were invited to take part in the study through announcements in teaching sessions. Orientation sessions were held for those students who volunteered, where ethical issues were discussed and guidance provided as to what we would particularly like them to reflect on in their diaries. This included times when they began to see things differently, suddenly grasped something or where they were struggling to understand an issue, as well as any factors that they felt helped or hindered their learning. Students recorded audio-diary reflections directly after social engagement sessions. These were uploaded to a secure site, transcribed and analysed.

Data were analysed thematically, using QSR NVivo software. Transcripts were read and reread and descriptive themes identified and refined through a cyclical, iterative and consensual process of reading and team discussion to reach a final coding scheme. On noting that participants' reflective logs tended to follow a similar 'plot' structure, we subsequently undertook a structural narrative analysis of participants' journeys through the pathway. Each participant's reflections were read in chronological order and fluctuations in activity and emotions noted to sketch out the shape of the narrative therein [12]. 


\section{Results}

Fourteen Year 2 dental $(n=8)$ and Year 3 medical students $(n=6)$ recorded 50 audio reflections. Seven participants were male and seven female. Dental students submitted 33 recordings and medical students submitted 17.

\section{Thematic analysis}

A major theme running through the diaries was the strong emotions described by students as the projects progressed. Other themes related to evidence of learning (improved communication skills, self-development, appreciation of others' lives and the services available) and critical reflection (about themselves, their assumptions and wider societal issues). These are described in Tables 1 and 2 along with illustrative quotes.

[Table 1 near here]

[Table 2 near here]

\section{Narrative analysis}

When read in chronological order, participants' reflections took the shape of a narrative that consistently followed a three-act structure; a structure commonly used in film and storytelling [13]. In this study, the participants' emotions and thoughts (identified as a major theme above), varied throughout their narratives; with various types and levels of emotion associated with each act.

\section{Act One}


Act One provides context and presents an 'inciting incident' or challenge for the characters, which then drives the story. In this study, Act One relates to the first two milestones, where students start to get to grips with the challenges of a new learning environment, including the need to undertake research, preparation and develop ideas for their intervention. When discussing their experiences, students described a range of feelings including apprehension and uncertainty.

Prior to the visit there was some anxiety and trepidation about finding the location and representing the university well (Ayesha, Dental)

The social engagement project is quite different from other projects because it's quite unstructured... ... it's good because it gives a lot of freedom to us to use our imagination to do a project, but then it's also difficult because really we're mostly used to placements at the hospital where the routine is rather similar (James, Medical)

The inciting incident occurred as students made first contact with their allocated community organisation and service users and took part in meetings. As they struggled to come up with an idea, they described rising levels of emotions such as anxiety and confusion. Having to change or adapt ideas led to frustration and sometimes disappointment.

I was a bit nervous about meeting the service users, cos I'd never really interacted with homeless people (Alicia, Medical)

We were a bit confused and anxious that all our plans that we'd come up with have been wiped away. So it was a little bit difficult to understand what we had to do (Hamaad, Dental) 
We didn't know whether we were meant to talk to the parents or play with the children... ... so we kind of tried to keep it a mixture (Sofia, Medical)

Students often realised their ideas needed to change and adapt;

The only challenge today is that now we have seen our location and met other staff members we now know that children will be 18 months to two years... ... we [have] have to adjust our diet interactive session as this was aimed at three to five year olds. (Karin, Dental)

We went in with many ideas of how to target children... ... We quickly learned though ...that the number of people we target was not really as important as the impact that we should have on the people after we've delivered the project (Sam, Dental)

\section{Act Two}

Act Two, is known as the 'confrontation' or 'pre-climax'. It is characterised by rising action, tension and emotion as the protagonist(s) try to confront the challenge from the first act. Their attempts are often unsuccessful, and they must learn new skills and gain greater insights in order to tackle this. In this study it relates mainly to the second and third milestone sessions where participants learnt more about the community's needs, attempted to crystallise their ideas for an intervention and presented it to staff at the community organisation for feedback. 
At this point our project has opened up, there's lots of questions but we have to narrow it back down now to something which is a bit more do-able for just one week. (Min-Joon, Medical)

I've definitely got more direction today because talking to [service users] I can kind of see where the research should go. (Becky, Medical)

Students often reported initial difficulties working as a team, which usually improved over time.

As a group at first we were struggling to work together, people had different ideas and stuff but I feel like now we've come towards a common goal. (Ollie, Dental)

So by the end of our meeting and further brainstorming we'd reorganised our team roles and felt quite proud of what we've been able to achieve overcoming that challenge and getting back on track. (Ayesha, Dental)

As intervention day approached, it was accompanied by a surge in emotions: discomfort at approaching unfamiliar groups, confidence and even excitement when it appeared the intervention would work, and may have a positive impact

One big worry of mine at the moment is how we will make the session interactive and keep all of the kids engaged, because this is the first time that all of us are going to go into a school and tackle teaching and interacting with 40 students. (Niall, Dental)

I can really see our project making a positive difference in the community. We'll be teaching the children how to take good care of their oral health and they'll be teaching others, and it would be just a domino effect to teaching more and more people. (Sam, Dental) 


\section{Act Three}

The third act is the 'climax' and 'resolution'. In the climax, the rising tension peaks, the central challenge is confronted and the question raised by the inciting incident is answered. As the story and the emotions wind down, it is often clear that the protagonist(s) has changed in some way, gaining a new sense of identity or purpose. The intervention day, milestone session 4, was the climax of the third act in this study. Students commonly described strong emotions. Successful delivery of an intervention was reported as 'rewarding', 'exciting' or 'enjoyable', with students also describing pride in themselves and their team and even relief.

We were allowed to form the whole project and by the end have this really good intervention and we genuinely do feel as if we have given back to the community. (Hamaad, Dental)

This was particularly true where the intervention required a public presentation or when they felt they had developed as people or received positive feedback

Yesterday was absolutely amazing really, the children and the adults really enjoyed it, really engaged... [[the Family Project leader] was really impressed and always complementary]. The kids were absolutely amazing, really enthusiastic, wanted to learn, and had a lot of fun, and I think the parents appreciated as well. (Karl, Dental)

The facilitators were really happy with our progress, said we were really organised and that we'd done a lot of work, and we'd come a long way from the first meeting where none of us really knew which direction to go in. (Ollie, Dental)

Others felt their intervention could, have been more effective or that, in hindsight, they would have conducted their intervention differently 
Now I've come home and had a little think about it I kind of wish we'd asked more questions about the community and got to know the area a bit better (Nozomi, Medical)

Just that sometimes it could feel a bit pointless in a way if it doesn't get developed, and maybe we could have come up with a better idea (Alicia, Medical)

Some participants raised concerns, or highlighted issues about the fate of the community they had worked with, particularly whether their work would address the group's problems or be long-lasting.

I feel that this project has been beneficial to me as a student, although I'm not convinced that I've had much impact on the community. (Karin, Dental)

I don't feel like... ...the resource we were trying to create this week would be of much benefit in terms of helping them access healthcare, and I feel it's more of a bigger problem in terms of finding them a home and hopefully that would lead to them finding work and having more stability in their lives. (Alicia, Medical) ...hopefully now they [dental champions] will be willing to pass on their knowledge as well in the future so we have a bit more of a lasting impact and it won't just be a one day thing. (Ollie, Dental)

There was evidence that community project staff, facilitators and feedback from service users were key to supporting students through the pathway challenges and facilitating their learning We got to present our ideas to him [Project Lead], hear what he thought about it and then also modify or change any of the ideas we had. (Jodie, Dental) 
He [Headmaster] has facilitated us very well in terms of helping us to shape our idea. (Niall, Dental)

She [facilitator] asked some interesting questions I guess in terms of what we felt we'd learnt from it, going to [homeless service], and any barriers we saw in them accessing healthcare. (Alicia, Medical)

\section{Discussion}

This study suggests that an educational pathway, which offers students opportunities to learn directly from, and with, disadvantaged communities is a valuable teaching intervention. All students described developing skills and knowledge, particularly around project development, working as a team and communication. They demonstrated critical thinking, for example around societal issues and about the sustainability and value of their intervention and described having their assumptions challenged. Both medical and dental students frequently used language such as 'eye opening', being 'surprised', 'shocked' or made to think. Some reported both their perceptions and they themselves being changed; suggesting that, for them, the learning was transformational. The nature of this learning seemed to relate more to the population group students were working with than whether they were medical or dental. In line with studies on transformative learning [14], immersion in new contexts, forming connections with others, having one's worldview challenged and plans going wrong, all appeared to facilitate shifts in thinking, as did experiencing negative emotions. Adaptability, interaction with service users and support and feedback helped students address challenges, which was usually associated with positive emotion. A strength of this study is that the combination of narrative and thematic analysis enabled identification of themes in both content and form of students' accounts; this thorough approach is recommended by narrative researchers [15]. Further, male, female, dental and medical students' views were all 
represented. A notable limitation is that the data come from a small cohort of 14 participants in one University, so the results may not be representative or generalisable to other settings.

One aim of this pathway was for students to learn more about the social determinants of health $(\mathrm{SDOH})$ and how they impact particular population groups. A recent paper suggested that within medical schools, $\mathrm{SDOH}$ are often presented as 'facts to be known' rather than as 'conditions to be challenged and changed' [16,p.25]. They argue that an aim of such education should be to train health professionals who can participate in social change and take action to address inequities in health. They suggest that discussion about SDOH in medical education often fails to examine issues such as power and privilege or promote critical thinking about justice and inequity. In our study, however, there was evidence of students' reflecting on their privilege, questioning their assumptions, thinking critically about the issues underpinning inequalities and asking questions about the meaning of SDOH for their population groups. This suggests that pathways such as these could be important catalysts for promoting critical discussion around $\mathrm{SDOH}$, particularly if this is built on in future years.

A uniqueness of these pathways is the delivery by an established community health charity. This helps ensure that the learning experiences and projects are developed in genuine partnership with local organisations and their users. A limitation is that each learning pathway only lasts four days in a single year and we do not know whether students' shifts in understanding are enduring. Our dental students do have opportunities in later years to build on this learning and we are exploring ways of providing similar experiences for later years' medical students. While the dental and medical student pathways currently run independently, a future goal is for these learning pathways to become inter-professional, 
perhaps with teams made up of a range of health students. Understanding the 'acts' that students commonly experience when taking part in such pathways can provide useful insights for educators and facilitators. Sharing these findings with our community partners has reinforced the importance of accepting students' emotional responses as an important part of their learning process, enabling them to support students appropriately at each stage.

\section{Conclusion}

Educators often work hard to remove challenges and make learning 'easier' for students. This study suggests that unsettling contexts, negative emotions and obstacles may facilitate transformative learning around social accountability, population health needs and inequalities, as long as students are appropriately supported through this process.

Ethical Approval for this study was obtained from the University of Plymouth Health and Human Sciences Approval Panel (16/17)-633

Words 2811

[1] Rourke J. AM Last Page: Social Accountability of Medical Schools. Academic Medicine. 2013; 88(3):430.

[2] The Global Consensus of Social Accountability of Medical Schools. 2010. Available from: http://healthsocialaccountability.org/

[3] Reeve C, Woolley T, Ross SJ, et al. The impact of socially-accountable health professional education: A systematic review of the literature. Medical Teacher. 2017;39(1):67-73. 
[4] McCrea ML, Murdoch-Eaton D. How do undergraduate medical students perceive social accountability? Medical Teacher. 2014;36(10):867-875.

[5] Batra M, Shah AF, Danuy S, et al. Social accountability: the missing link in dental education. International Archives of Integrated Medicine. 2015;2(1):137-140.

[6] Chen V, Foster Page L, McMillan J, et al. Measuring the attitudes of dental students towards social accountability following dental education-qualitative findings. Medical Teacher. 2016;38(6):599-606.

[7] Webb L. Sandhu S, Morton L, et al. A dental student view on learning gained through Inter-Professional Engagement with people experiencing homelessness. Education for Primary Care. 2019;30(5):319-321.

[8] Davis L, Kind C. Letter: Tackling stigma in medical professionals: the need for a social engagement programme in medical education. Education for Primary Care. 2019;30(5):328. [9] Perkins D. 2006. Constructivism and troublesome knowledge. In: J Meyer \& R Land, editors. Overcoming barriers to student understanding: Threshold concepts and troublesome knowledge. London \& New York: Routledge. p. 33-47.

[10] Williamson I, Leeming D, Lyttle S, et al. Evaluating the audio-diary method in qualitative research. Qualitative Research Journal. 2015;15(1):20-34.

[11] Neve H, Lloyd H, Collett T. Understanding students' experiences of professionalism learning: a 'threshold' approach. Teaching in Higher Education. 2016;22(1):92-108. [12] Lieblich A, Tuval-Mashiach R, Zilber T. Narrative Research: Reading, Analysis and Interpretation. London: Sage Publications; 1998.

[13] Masterclass: How to write a three-act structure; [updated 2019 Nov 22]. Available from: https://www.masterclass.com/articles/how-to-write-three-act-structure\#an-example-of-threeact-structure 
[14] Van Schalkwyk S, Hafler J, Brewer T, et al. Transformative learning as pedagogy for the health professions: a scoping review. Medical Education. 2019;53(6):547-558.

[15] Hiles D, Cermák I. Narrative psychology. In: C. Willig \& W. Stainton-Rogers, editors. The SAGE handbook of qualitative research in psychology. Thousand Oaks (CA): SAGE Publications Ltd; 2008. p. 146-162.

[16] Sharma M, Pinto AD, Kumagai AK. Teaching the social determinants of health: a path to equity or a road to nowhere? Academic Medicine. 2018;93(1):25-30. 